\title{
Micro-spectroscopic investigation of selenium-bearing minerals from the Western US Phosphate Resource Area
}

\author{
Amy L. Ryser and Daniel G. Strawn ${ }^{\mathrm{a})}$ \\ University of Idaho, Moscow, Idaho 83844-2339 \\ Matthew A. Marcus \\ Lawrence Berkeley National Laboratory, Berkeley, California 94720 \\ Jodi L. Johnson-Maynard, Mickey E. Gunter, and Gregory Möller \\ University of Idaho, Moscow, Idaho 83844-2339
}

(Received 14 September 2004; accepted 8 December 2004; published online 28 January 2005)

\begin{abstract}
Mining activities in the US Western Phosphate Resource Area (WPRA) have released Se into the environment. Selenium has several different oxidation states and species, each having varying degrees of solubility, reactivity, and bioavailability. In this study we are investigating the speciation of $\mathrm{Se}$ in mine-waste rocks. Selenium speciation was determined using bulk and micro-X-ray absorption spectroscopy (XAS), as well as micro-X-ray fluorescence mapping. Rocks used for bulk-XAS were ground into fine powders. Shale used for micro-XAS was broken along depositional planes to expose unweathered surfaces. The near edge region of the XAS spectra (XANES) for the bulk rock samples revealed multiple oxidation states, with peaks indicative of $\mathrm{Se}(-\mathrm{II}), \mathrm{Se}(\mathrm{IV})$, and $\mathrm{Se}(+\mathrm{VI})$ species. Micro-XANES analysis of the shale indicated that three unique Se-bearing species were present. Using the XANES data together with $a b$ initio fitting of the extended X-ray absorption fine structure region of the micro-XAS data (micro-EXAFS) the three Se-bearing species were identified as dzharkenite, a di-selenide carbon compound, and Se-substituted pyrite. Results from this research will allow for a better understanding of the biogeochemical cycling of Se in the WPRA. (C) 2005 American Institute of Physics. [DOI: 10.1063/1.1852751]
\end{abstract}

\section{INTRODUCTION}

Approximately $40 \%$ of the United States phosphate reserves are located in southeast Idaho, northern Utah, and western Wyoming $^{1}$ in an area known as the Western Phosphate Resource Area (WPRA). The phosphate ore in the WPRA is located in the Meade Peak Member of the Phosphoria Formation dating to the Permian period. Approximately $6 \times 10^{6} \mathrm{Mg}$ of ore is extracted annually from this area resulting in $36 \times 10^{6} \mathrm{Mg}$ of waste material. ${ }^{1}$ Rex Chert and Cherty-Shale Members overlay the Phosphoria Formation and Pennsylvanian period Wells Formation (limestone) lies below the Phosphoria Formation. The Phosphoria Formation contains two ore zones. Typical thickness of the upper and lower ore zone is 6-14 m, with $23-55 \mathrm{~m}$ of phosphatic shales (middle waste shale) separating the two ore zones. ${ }^{1,2}$

The near-surface middle waste shale contains high levels of Se (Fig. 1). Prior to 1998, a standard reclamation practice within the WPRA was to mix the shale-waste material and redeposit it back onto the mine site. Through this practice Se was removed from a slow weathering environment and placed into one that is much more dynamic with respect to water and biological activity. ${ }^{3,4}$ Increased weathering causes changes in the Se speciation in the reclaimed sites, with the more soluble oxidized Se species favored.

Selenium is an essential micronutrient with a narrow range between sufficiency and toxicity. ${ }^{5}$ In the environment,

${ }^{a}$ Electronic mail: dgstrawn@uidaho.edu birds, hoofed animals, and aquatic species are particularly sensitive to Se, and may show chronic or acute signs of toxicity. Bioavailability is dependent on solubility, which also controls Se mobility through the ecosystem. Thus, in order to manage risks and remediation of the soils derived from the Se containing rocks in the WPRA better knowledge of Se speciation in the parent materials is necessary.

Selenium exists in multiple oxidation states, with each state having different fates within the environment. Selenides $[\mathrm{Se}(-\mathrm{II})]$ and elemental $\mathrm{Se}(0)$, which are reduced forms of $\mathrm{Se}$, are formed under anaerobic conditions, and are not considered to be mobile or bioavailable. ${ }^{6}$ Selenite $\left(\mathrm{SeO}_{3}^{2-}\right)$ and selenate $\left(\mathrm{SeO}_{4}^{2-}\right)$ are more soluble than the reduced Se species. Selenite forms adsorption complexes on ferric oxide complexes, which are not readily bioavailable. ${ }^{7}$ Selenate is the most soluble Se species and is readily taken up by plants and leached through the soil profile. ${ }^{8}$ Distribution of selenite and selenate between the solid and solution phases within soil has been shown to be a function of $p \mathrm{H}^{9}{ }^{9}$

Past work conducted in the WPRA identified a number of Se-bearing species in shale material, and found substantial heterogeneity. Desborough ${ }^{10}$ analyzed samples from a "carbon seam" at Maybe Canyon mine in Idaho by electron microprobe, x-ray diffraction, and bulk chemical analysis and concluded that the shale samples contained no pyrite, suggesting that the selenium in the rock was associated with organic material. In contrast, samples from the Dry Valley Mine (within the WPRA) contained both framboidal and angular pyrite, with Se concentrations ranging from $<100$ (de- 


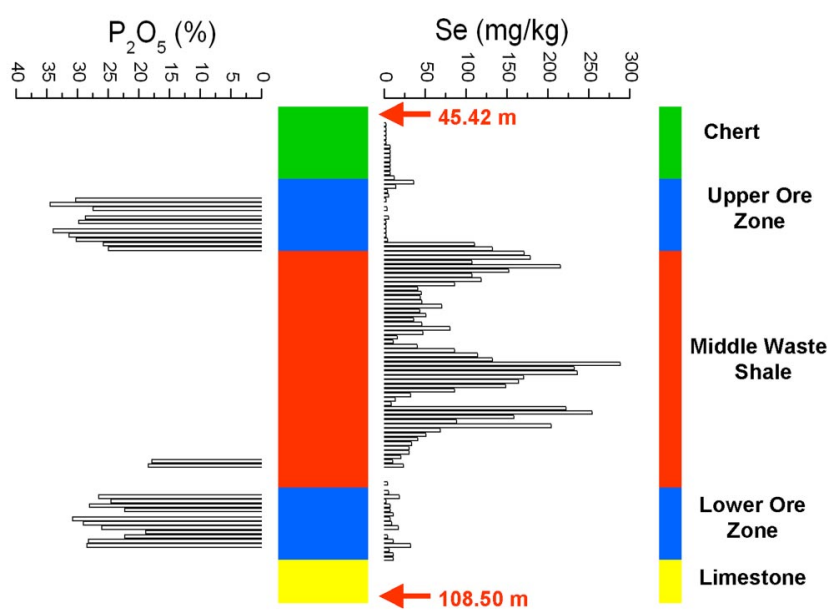

FIG. 1. (Color) Exploration drilling core profile from analyses of $\mathrm{P}_{2} \mathrm{O}_{5}$ and total Se in the sedimentary profile of the Meade Peak Member of the Phosphoria Formation near the Smoky Canyon Mine, Caribou County, ID. Horizontal bar graph indicates concentrations in $0.6 \mathrm{~m}$ sections. Adapted from Munkers (Ref. 30).

tection limit) to $2000 \mathrm{mg} \mathrm{kg}^{-1}$. ${ }^{4}$ By using a combination of x-ray absorption near edge spectroscopy (XANES) and sequential-extraction techniques, Perkins and Foster ${ }^{11}$ determined that in unweathered, or minimally weathered shale samples from the WPRA, the largest fraction of Se was associated with iron sulfides. Most of the non-sulfideassociated Se was associated with organic matter and oxyhydroxides, and a small amount of Se was present in elemental form. In weathered shale samples the dominant form of Se observed was $\mathrm{Se}(\mathrm{IV})$ associated with oxyhydroxides.

Nondestructive X-ray spectroscopic methods such as x-ray absorption fine structure (XAFS) spectroscopy are powerful tools in studying Se speciation. ${ }^{12}$ However, the heterogeneity that exists in natural samples often makes it difficult to interpret speciation using bulk-XAFS spectroscopy. In recent years the development of microscopically resolved XAFS spectroscopy has created new opportunities for interpreting speciation and spatial heterogeneity within natural materials. Micro-XAFS techniques, for example, can be used to obtain chemical and structural information on the micrometer-scale typical of mineral grains. ${ }^{13}$ Manceau et al. ${ }^{13}$ suggest that even though the nanoscale detail cannot be seen with micrometer size probes, such as micro-XAFS spectroscopy, it can be inferred with confidence. Strawn et al. ${ }^{14}$ used micro-XAFS spectroscopy to identify two iron aggregates that were located within a few microns of each other in undisturbed soil samples. They were also able to determine that As and Se were more concentrated in iron oxide aggregates rather than the clay/shale matrix. Tokunaga et al. ${ }^{15}$ also used micro-XANES to obtain spatially resolved distribution maps of Se oxidation states in natural samples. In the research presented in this paper we use micro-XAFS spectroscopy to investigate the species of Se present in the middle waste shale from the Meade Peak Member of the Phosphoria Formation.

\section{MATERIALS AND METHODS}

\section{A. Sample collection}

We collected shale samples from the Smoky Canyon mine in The Caribou National Forest in southeastern Idaho. For micro-XAFS analyses a shale rock was used that had no visible fractures, implying that the interior was unweathered. The shale was broken along depositional planes to expose fresh surfaces. Two separate surfaces were prepared for analysis (referred to as samples 1 and 2). The bulk Se concentration in the shale was $140 \mathrm{mg} \mathrm{kg}^{-1}$. A second shale sample with a concentration of $34 \mathrm{mg} \mathrm{kg}^{-1}$ was ground to fine powder for bulk XAFS spectroscopy (referred to as ground shale-Smoky Canyon).

Rock samples that displayed a range of weathering classes were collected from the central part of Rasmussen Ridge mine, Dry Valley mine, and the Sage Creek Canyon area, Idaho as part of an extensive study carried out by the United States Geological Survey (USGS). ${ }^{16-19}$ The samples collected by the USGS are described as being least, less, and more weathered depending on their location (depth) to the original premined ground surface. Preparation of the samples involved air drying, grinding, and homogenizing $0.5-1 \mathrm{~kg}$ of rock material. Mineralogical characterization of these samples, along with complete chemical composition, are reported elsewhere. ${ }^{3,16-19}$ We analyzed select samples from this collection using bulk XAFS spectroscopy. Selected

TABLE I. Description of bulk rock samples used in this study collected by USGS (see Sec. II A).

\begin{tabular}{lccccccc}
\hline \hline $\begin{array}{l}\text { Sample } \\
\text { No. }\end{array}$ & $\begin{array}{c}\text { Weathered } \\
\text { classification }\end{array}$ & $\begin{array}{c}\text { Unit within mead } \\
\text { peak member }\end{array}$ & $\begin{array}{c}\mathrm{As} \\
\left(\mathrm{mg} \mathrm{kg}^{-1}\right)\end{array}$ & $\begin{array}{c}\mathrm{Cu} \\
\left(\mathrm{mg} \mathrm{kg}^{-1}\right)\end{array}$ & $\begin{array}{c}\mathrm{Se} \\
\left(\mathrm{mg} \mathrm{kg}^{-1}\right)\end{array}$ & $\begin{array}{c}\mathrm{Fe} \\
(\%)\end{array}$ & $\begin{array}{c}\mathrm{C} \\
(\%)\end{array}$ \\
\hline WSPA080C & More & Middle waste shale & 27.3 & 62.0 & 216 & 1.18 & 8.01 \\
WSPB131C $^{\mathrm{a}}$ & Less & Phosphorite & 9.50 & 94.0 & 1070 & 0.84 & 12.3 \\
WPSC155C $^{\mathrm{b}}$ & More & Upper waste shale & 17.4 & 41.0 & 259 & 2.49 & 2.74 \\
WPSD098C $^{\mathrm{b}}$ & Less & Middle waste shale & 32.9 & 2.88 & 193 & 1.63 & 19.1 \\
WPSE131C $^{\mathrm{c}}$ & More & Upper waste shale & 6.60 & 157 & 277 & 1.76 & 8.20 \\
WPSH047C $^{\mathrm{d}}$ & Less & Phosphorite & 15.6 & 196 & 413 & 0.79 & 12.3 \\
WPSH053C $^{\mathrm{d}}$ & Less & Phosphorite & 23.4 & 105 & 708 & 1.19 & 12.2 \\
WPSJ006C $^{\mathrm{d}}$ & Least & Footwall siltstone & 39.9 & 111 & 254 & 1.57 & 9.88 \\
WPSJ186C & Least & Upper waste & 13.1 & 55.0 & 445 & 1.36 & 4.27 \\
\hline \hline
\end{tabular}

${ }^{\mathrm{a}}$ Reference 16.

${ }^{\mathrm{b}}$ Reference 19.

${ }^{\mathrm{c}}$ Reference 17.

${ }^{\mathrm{d}}$ Reference 18 . 
chemical composition data from samples used for bulk rock XAFS are listed in Table I.

\section{B. Standards}

Selenium standards, purchased from Alfa Aesar or Sigma Aldrich, included selenium sulfide, copper selenide, zinc selenide, selenomethionine, sodium selenate, sodium selenite, orthogonal (gray) elemental selenium, selenocystine, Se-methyl-selenocysteine, and selenoethinoine. The minerals berzelianite, chalcomenite, krutaite, mandarinoite, and penroseite were purchased from the Excalibur Mineral Company (New York). Ferroselite was synthesized following the procedures described by Warren,${ }^{20}$ and checked by powder x-ray diffraction to confirm its crystal structure. Monoclinic (red) elemental selenium was made by microbial reduction of selenite. Standards used for XAFS spectroscopy were diluted in boron nitride.

\section{X-ray spectroscopy}

Micro-XAFS spectroscopy and fluorescence microprobe mapping were done on beamline 10.3.2 at The Advanced Light Source (ALS), Lawrence Berkeley National Laboratory (Berkeley, CA). Beamline 10.3.2 is designed to map elemental distributions and collect XAFS data on small areas. A seven-element germanium detector was used to measure sample fluorescence. A monochromatic x-ray beam tunable to energies from 2.0 to $17 \mathrm{keV}$ using a $\mathrm{Si}(111)$ crystal set is focused on the sample using a Kirkpatrick-Baez mirror pair. ${ }^{21}$ The shale samples were attached to the sample holder using double-sided tape and the sample holder is attached to an $X Y$ stage that is oriented $45^{\circ}$ to the beam.

For elemental mapping micro-synchrotron x-ray fluorescence (micro-SXRF) was used. For sample 1, the elemental distribution map was collected using a beam focused to $5 \times 5$ $\mu \mathrm{m}$ (horizontal and vertical dimensions, respectively) rastered across the sample at $5 \mu \mathrm{m}$ intervals. The elemental distribution map for sample 2 was collected in the same manner as sample 1, except the beam size was $10 \times 10 \mu \mathrm{m}$ and step size was $7 \mu \mathrm{m}$. Dwell time on each spot was 100 $\mathrm{ms}$. The beam energy was tuned to $12757 \mathrm{eV}$. The windowed (regions of interest) $\mathrm{x}$-ray fluorescence counts for $\mathrm{Ca}, \mathrm{Cr}, \mathrm{Cu}$, $\mathrm{Fe}, \mathrm{Se}, \mathrm{Ti}$, and $\mathrm{Zn}$ were collected as the sample rastered through the beam. To determine the relationship between $\mathrm{S}$, $\mathrm{Fe}$, and $\mathrm{Ca}$ in sample 1 the beam was tuned to $\sim 3988 \mathrm{eV}$ with a beam spot size of $6 \times 6 \mu \mathrm{m}$ (relying on harmonics to excite the $\mathrm{Fe}$ and $\mathrm{Ca} K$ edges).

All spectra were collected at room temperature. Select Se standards were measured on beamline 10.3.2. Additional selenium standards and the powdered shale samples were measured on beamline X-11b at The National Synchrotron Light Source (NSLS) at Brookhaven National Laboratory, Upton, NY. Energy is focused at this beamline using a $\mathrm{Si}(111)$ monochromator. Transmission spectra from Se standards diluted in boron nitride were collected using $\mathrm{N}_{2}$-filled ionization detectors. Fluorescence spectra from the powdered reference materials were collected on beamline $\mathrm{X}-11 \mathrm{~b}$ using a krypton purged Stern-Heald type detector. ${ }^{22}$ A Se(0) standard (orthorhombic Se, Sigma Aldrich) was run either be- tween samples (beamline 10.3.2) or in situ (X-11b) for energy calibration. The XAS data were averaged (three to seven scans), normalized, and background subtracted using standard procedures in the program ATHENA. ${ }^{23}$ Step size through the XANES regions was $0.70 \mathrm{eV}$. Measurement of the standard deviation of the edge energies from several points of interests with the same XANES features between two separate beamtime runs indicated that the edge-energy precision was less than the step size. Thus we estimate that the calibrated data are accurate to within $0.70 \mathrm{eV}$. Extended $\mathrm{x}$-ray absorption fine structure (EXAFS) data were transformed into $k$ space ( $\chi$ spectra) using the sample absorption edge. Finally the data were transformed into frequency distributions by Fourier transforming (FT) the data using square windows.

The EXAFS data were fit using theoretical backscattering amplitudes and phase shifts calculated in the program FEFF $8.0^{24}$ using the unit cell and space groups for dzharkenite (FeSe ${ }_{2}$, pyrite structure) or Se-substituted pyrite. Fitting was done in WINXAS. ${ }^{25}$ The amplitude reduction factor was fixed to 1 , which was derived from optimizing the fit of monoclinic elemental Se. Coordination numbers were fixed at values appropriate for the atomic shells from the mineral that most closely simulated the unknown EXAFS spectra. This is consistent with the approach used to fit overlapping first shells in arsenic sulfides. ${ }^{26} \mathrm{We}$ also used the results from the XANES analyses to help guide the atomic-shell selections. To determine which models best simulated the unknown spectra we fit the first peak in the FT with two shells of Fe and either Se or S. Then, based on first shell fit results, we deduced which mineral the atomic distances most closely matched, added the additional atomic shells, fixed coordination numbers, and allowed the Debye-Waller factors and bond distances to vary. Fixing the coordination numbers was necessary so that the degrees of freedom did not exceed the number allowed during the fitting procedure. Additionally, to reduce the number of atomic shells necessary to fit the data we assumed that atomic shells with the same atoms that were closer than $\sim 0.2 \AA$ could be fit as a single shell. Bond distances derived from fitting these shells represent weighted averages, and Debye-Waller factors reflect the deviation in the inter-atomic separations. The final best fit was derived based on the reduced chi square and qualitative agreement between the dominant features in the fit and the raw $\chi$ and FT spectra. As a result of the fitting we were able to compare atomic coordination environment and derived bond distances with those in theoretical minerals, and evaluate the relative local atomic disorder (the Debye-Waller factor) for each shell. Errors for bond distances were less than 3\% as estimated by comparing the fit-derived parameters for ferroselite EXAFS data to the theoretical values.

Principal component analysis was done on the microXANES spectra to determine the number of end members that comprise the 9 micro-XANES. The minimum of the indicator (IND), which is at a minimum when the correct number of significant components is reached, was used to assess the minimum number of components necessary to reproduce the spectral set. ${ }^{27}$ Target transforms using the number of components necessary to define the sample space was 


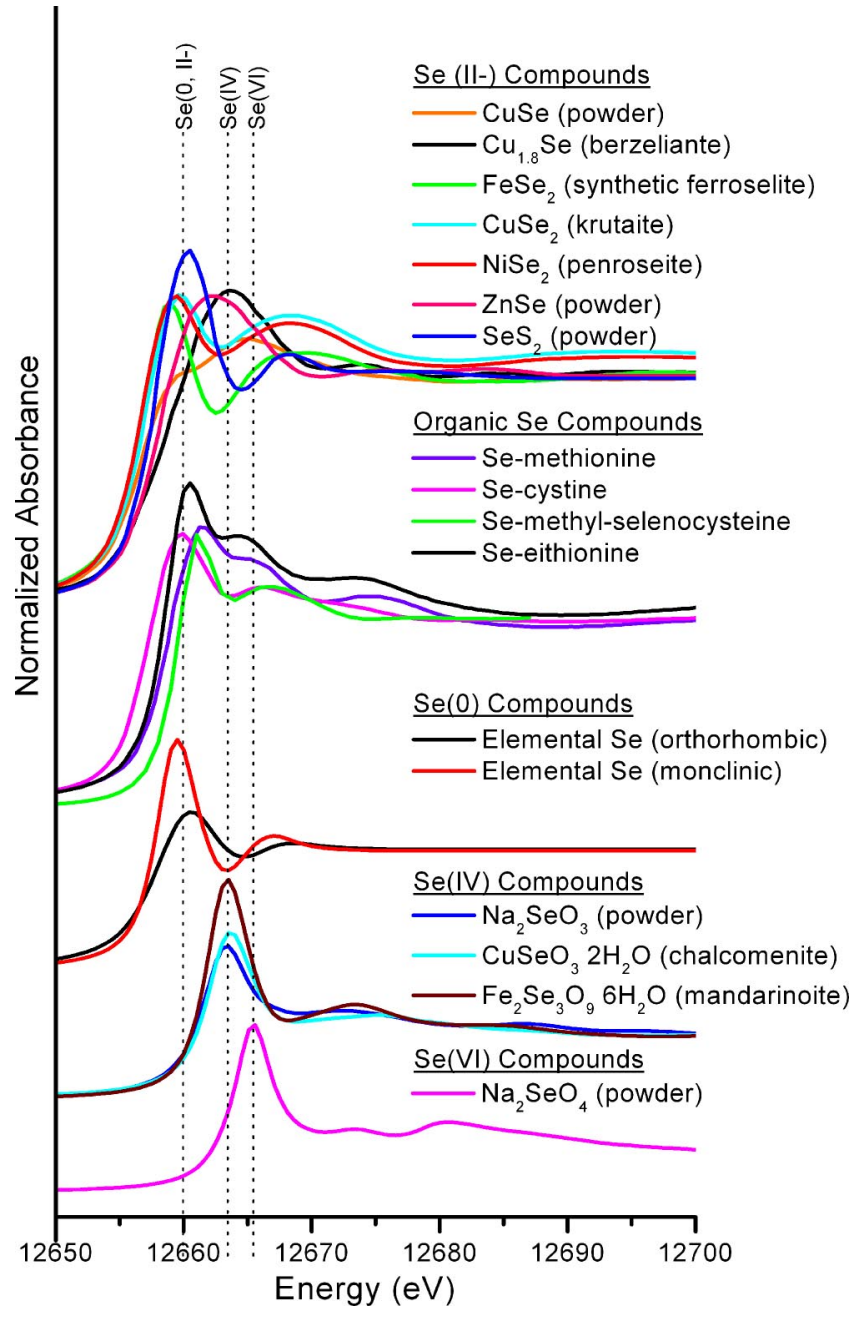

FIG. 2. (Color) Selenium XANES spectra for reference standards.

done to determine if the components could be matched with known reference compounds. To determine whether the target transforms were acceptable, moderately acceptable, or unacceptable, the SPOIL and the chi squared values were evaluated, as well as visual confirmation that the target was well defined by the components. ${ }^{27}$

\section{RESULTS AND DISCUSSION}

\section{A. XANES standards}

XANES data for several Se compounds are shown in Fig. 2. Apparent from the XANES of these compounds is that the white line (i.e., the peak) from the main $1 s \rightarrow 4 p$ transition varies not only as a function of valence, but also according to bonding partners. Typically XANES analysis is used to identify oxidation state based on the edge position. This is done by taking the maximum of the first derivative of the main edge. Table II lists the edge energies for the standard compounds, and known formal valence states. However, as has been shown for sulfur (a chemical analogue for $\mathrm{Se}$ ), electronic oxidation states as measured by XANES are not always consistent with formal oxidation states due to variations in actual electronic density resulting from varying degrees of covalent bonding. ${ }^{28}$ Thus, because of the high
TABLE II. Selenium $K$-edge energies for reference standards, based on maximum of first derivative of XANES spectra.

\begin{tabular}{|c|c|}
\hline Species & $K$-edge energy $(\mathrm{eV})$ \\
\hline \multicolumn{2}{|c|}{ Organic Se compounds } \\
\hline Se-cystine & 12657.5 \\
\hline Se-eithionine & 12659.0 \\
\hline Se-methionine & 12659.0 \\
\hline Se-methyl-selenocysteine & 12659.5 \\
\hline \multicolumn{2}{|c|}{$\operatorname{Se}(-$ II $)$ compounds } \\
\hline $\mathrm{CuSe}$ & 12656.0 \\
\hline $\mathrm{FeSe}_{2}$ (Synthetic Ferroselite) & 12657.0 \\
\hline $\mathrm{CuSe}_{2}$ (Krutaite) & 12657.0 \\
\hline $\mathrm{NiSe}_{2}$ (Penroseite) & 12657.0 \\
\hline $\mathrm{ZnSe}$ & 12656.5 \\
\hline $\mathrm{Cu}_{1.8} \mathrm{Se}$ (Berzelianite) & 12656.5 \\
\hline $\mathrm{SeS}_{2}$ & 12658.0 \\
\hline \multicolumn{2}{|c|}{ Se (0) compounds } \\
\hline Elemental Se (monoclinic) & 12658.0 \\
\hline Elemental Se (orthorhombic) & 12658.0 \\
\hline \multicolumn{2}{|c|}{ Se (IV) compounds } \\
\hline $\mathrm{Na}_{2} \mathrm{SeO}_{3}$ & 12662.0 \\
\hline $\mathrm{CuSeO}_{3} \mathrm{H}_{2} \mathrm{O}$ (Chalcomenite) & 12662.0 \\
\hline $\mathrm{Fe}_{2} \mathrm{Se}_{3} \mathrm{O}_{9} 6 \mathrm{H}_{2} \mathrm{O}$ (Mandarinoite) & 12662.0 \\
\hline \multicolumn{2}{|c|}{ Se (VI) compounds } \\
\hline $\mathrm{Na}_{2} \mathrm{SeO}_{4}$ & 12664.0 \\
\hline
\end{tabular}

degree of covalency in $\mathrm{Se}(-\mathrm{II})$ compounds, and the poorly defined formal oxidation states for some Se compounds (e.g., ferroselite, $\mathrm{FeSe}_{2}$ ), assignment of formal oxidation state based solely on edge position is tenuous. Pickering et al. ${ }^{12}$ noted that the Se $K$ edge is sensitive to variations in the local environment, including crystalline and aqueous forms of the same ion, and different elemental allotropes. The Se(IV) and $\mathrm{Se}(\mathrm{VI})$ compounds are not as susceptible to changes in edge energy.

Selenium standards had absorption $K$-edge energies between 12656.0 and $12664.0 \mathrm{eV}$ (Fig. 2 and Table II). In general, the reduced Se compounds have edge energies between 12656 and $12659.5 \mathrm{eV}$, which are significantly less than the $K$ edges of oxidized Se species [Se(IV) $=12662.0$ $\mathrm{eV}$ and $\mathrm{Se}(\mathrm{VI})=12664.0 \mathrm{eV}$ ]. For both allotropes of zerovalent Se the edge energy is $12658.0 \mathrm{eV}$. For the selenides the edge energies range between 12656.0 and $12658.0 \mathrm{eV}$. For the organic Se compounds the $K$-edge energies ranged from 12657.5 to $12659.5 \mathrm{eV}$. Although the edge energies for the standard compound classes overlap, the overall XANES for the compounds are distinct, indicating that Se-XANES is highly sensitive to oxidation state and local atomic coordination, and thus can be used to elucidate speciation.

\section{B. Elemental distributions}

Micro-SXRF mapping of the middle waste shale samples were done to determine the spatial elemental composition. Points of interests (POI) were selected from the elemental distributions maps, and either XANES or EXAFS 

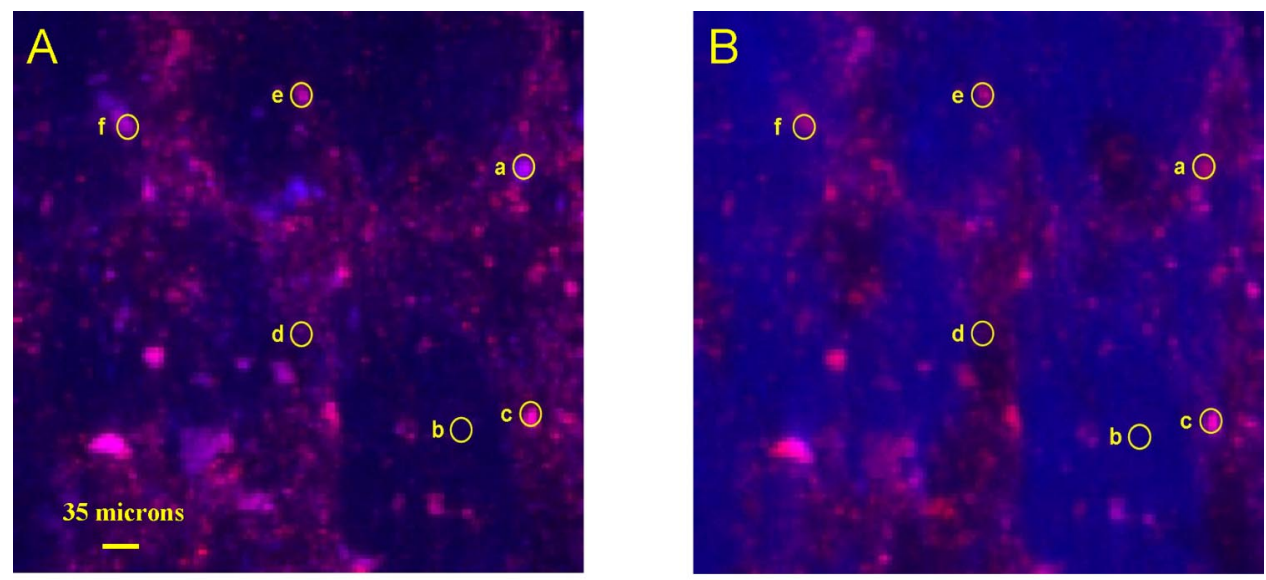

FIG. 3. (Color) Bi-color micro-SXRF map of middle waste shale sample 1 . In (a) $\mathrm{Se}$ is blue and $\mathrm{Fe}$ is red. In (b) $\mathrm{S}$ is blue and $\mathrm{Fe}$ is red. Letters on circles indicate points of interest (POI).

$\mathrm{Fe}$

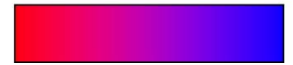

$\mathrm{Se} / \mathrm{S}$

spectroscopy data were collected for each POI. Figures 3 and 4 show the bi-color micro-SXRF elemental distribution maps for $\mathrm{Fe}$ and $\mathrm{Se}$ in samples 1 and 2.

The micro-SXRF spectra for spot $i$ is shown in Fig. 5. The $K \alpha_{1}$ peak for Se is located at $11222 \mathrm{eV}$. Iron, identified by the high intensity $K \alpha_{1}$ and $K \beta_{1}$ peaks at 6404 and 7058 $\mathrm{eV}$, respectively, dominates the spectra. Other peaks that can be identified in the XRF spectra are $\mathrm{Ca}\left(K \alpha_{1}=3692 \mathrm{eV}\right)$, $\mathrm{Cr}\left(K \alpha_{1}=5415 \mathrm{eV}\right), \quad \mathrm{Cu}\left(K \alpha_{1}=8048 \mathrm{eV}\right), \quad \operatorname{Ti}\left(K \alpha_{1}\right.$ $=4511 \mathrm{eV})$, and $\mathrm{Zn}\left(K \alpha_{1}=8639 \mathrm{eV}\right.$ and $\left.K \beta_{1}=9572 \mathrm{eV}\right)$. These elements (and others) have been observed in middle waste shale samples at varying concentrations. ${ }^{16-19}$

To assess whether there were significant correlations between Se and other elements in samples 1 and 2, elemental concentrations (intensity) from the micro-SXRF $x y$ scan were plotted against each other (Fig. 6). A positive relationship between Se and Fe for samples 1 and 2 existed. In both data sets there appears to be a population of data that have a decreased $\mathrm{Fe} / \mathrm{Se}$ ratio. XAFS spectroscopic analysis was done on points of interest that encompassed both populations. Selenium in samples 1 and 2 was also positively correlated to $\mathrm{As}, \mathrm{Cu}$, and $\mathrm{Mn}$ (data not shown). There was a positive correlation between $\mathrm{S}$ and Fe (Figs. 3 and 7) and a negative correlation between $\mathrm{S}$ and $\mathrm{Ca}$ (data not shown).

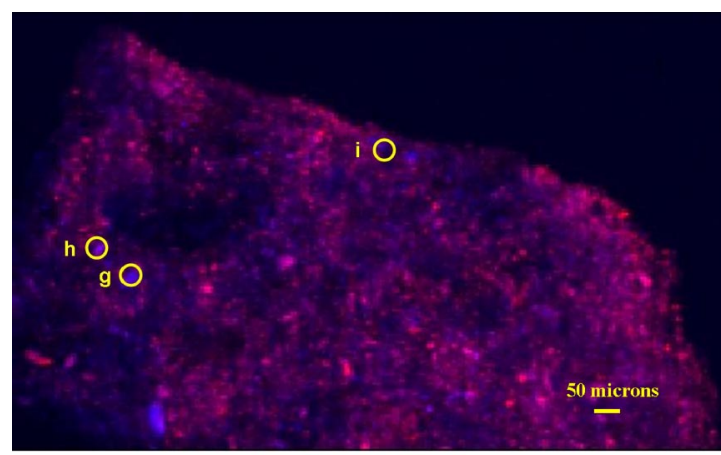

$\mathrm{Fe}$ $\mathrm{Se}$

FIG. 4. (Color) Bi-color micro-SXRF map of middle waste shale sample 2. Letters on circles indicate points of interest.
Electron microprobe analyses of siltstone/shale thin sections from the Smoky Canyon Mine in the WPRA were performed by Bond. ${ }^{29}$ This work identified pyrite and sphalerite grains in the rock, with pyrite comprising about $0.2 \%$ (by area) of the sample studied. Selenium was primarily associated with pyrite at concentrations approaching $0.7 \%$ (by mass) in the grains, fully accounting for the bulk Se concentration in the sample. Desborough et al. ${ }^{4}$ and Munkers ${ }^{30}$ used scanning electron microscope-energy dispersive spectroscopy (SEM-EDS) analysis and documented the presence of pyrite grains with both framboidal and cubic morphology in the middle waste shale, with total Se levels in the grains ranging from $0.1 \%$ to $3 \%$ (by mass).

Perkins and Foster ${ }^{11}$ used SEM-EDS and electron microprobe to analyze shale samples from the Meade peak formation. They observed that $\mathrm{Se}$ is associated with sulfide minerals, particularly iron sulfides such as pyrite. Perkins and Foster $^{11}$ further reported that selenium concentrations detected in pyrite were 10-100 times higher than concentrations observed in bulk-rock, with average rock concentra-

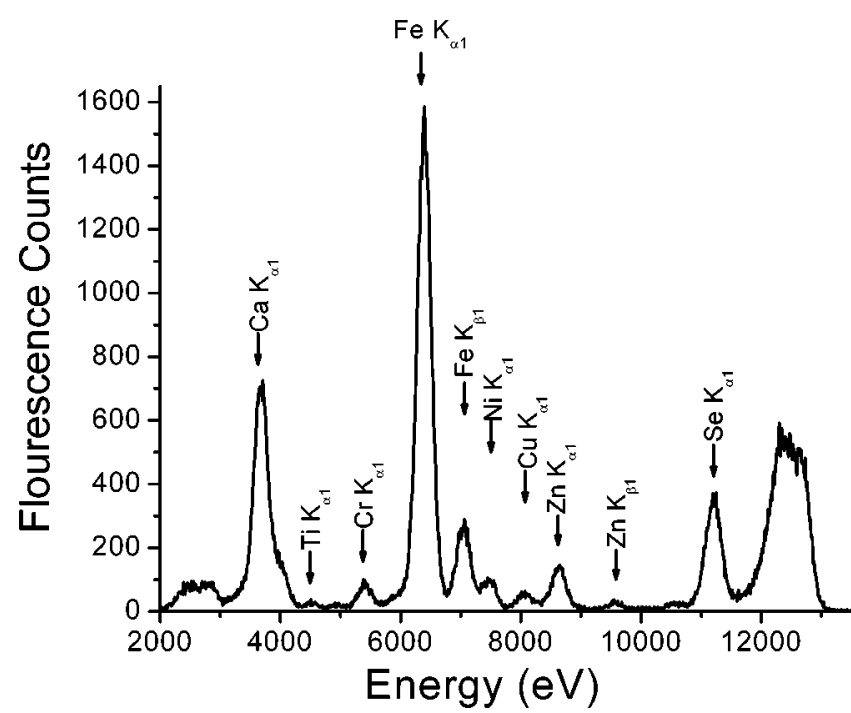

FIG. 5. X-ray fluorescence spectra collected from sample 2 POI $i$. 


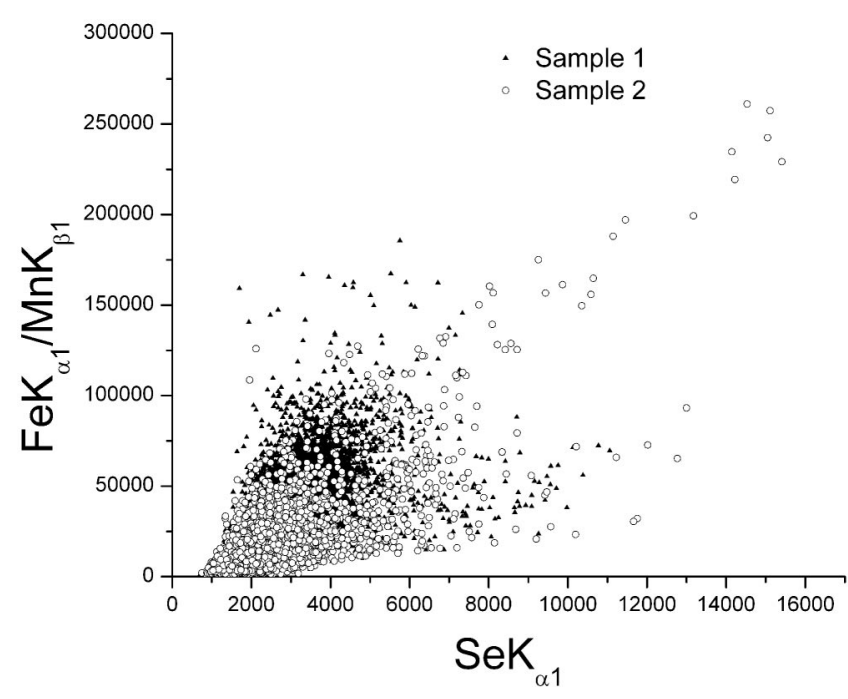

FIG. 6. Selenium and iron elemental associations from sample 1 and sample 2. Pearson correlation coefficients are 0.77 for sample 1 and 0.83 for sample 2. Counts on sample 2 are 0.1 of actual counts.

tions exceeding $2000 \mathrm{mg} \mathrm{kg}^{-1}$. Positive correlations between $\mathrm{Se}$ and $\mathrm{Cu}, \mathrm{Ni}, \mathrm{Cd}$, and $\mathrm{Zn}$ were also detected. ${ }^{11}$

Although a positive correlation for enrichment of Se in iron sulfide minerals and shale has been observed, speciation and mineralogy of Se in these materials is still unconfirmed. At best it is hypothesized that Se mirrors sulfur and forms similar minerals. The most thermodynamically stable iron selenide is ferroselite, which is isostructural to marcasite. ${ }^{31}$ Yakolvleva et al. ${ }^{32}$ used SEM-EDS, powder XRD, and bulk chemical analysis to study a supergene iron sulpho-selenide deposit associated with a massive copper-zinc sulfide ore deposit. They discovered a solid solution series of pyritedzharkenite $\left(\mathrm{FeS}_{2}-\mathrm{FeSe}_{2}\right)$ occurring in the weathering zone, suggesting that dzharkenite is a stable end member. Pyrite is the dominant iron sulfide mineral in the middle waste shale samples. Based on the micro-SXRF analyses of the freshly fractured rock surfaces, we hypothesize that most of the Se is

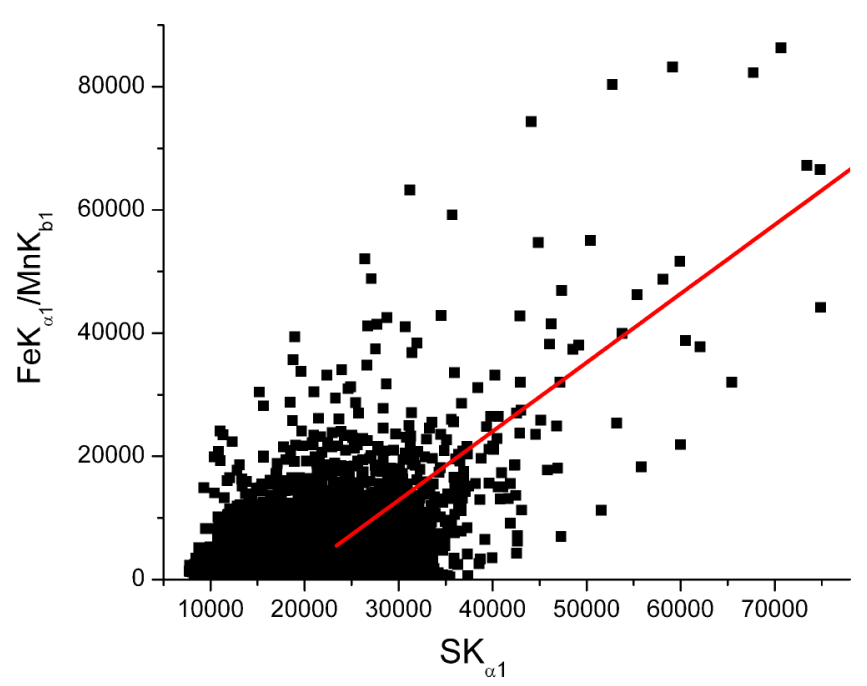

FIG. 7. (Color) Sulfur and iron elemental associations from sample 1. The red line represents the linear fit to all data that is 1 s.d. above the average, with a Pearson correlation coefficient of 0.70 .

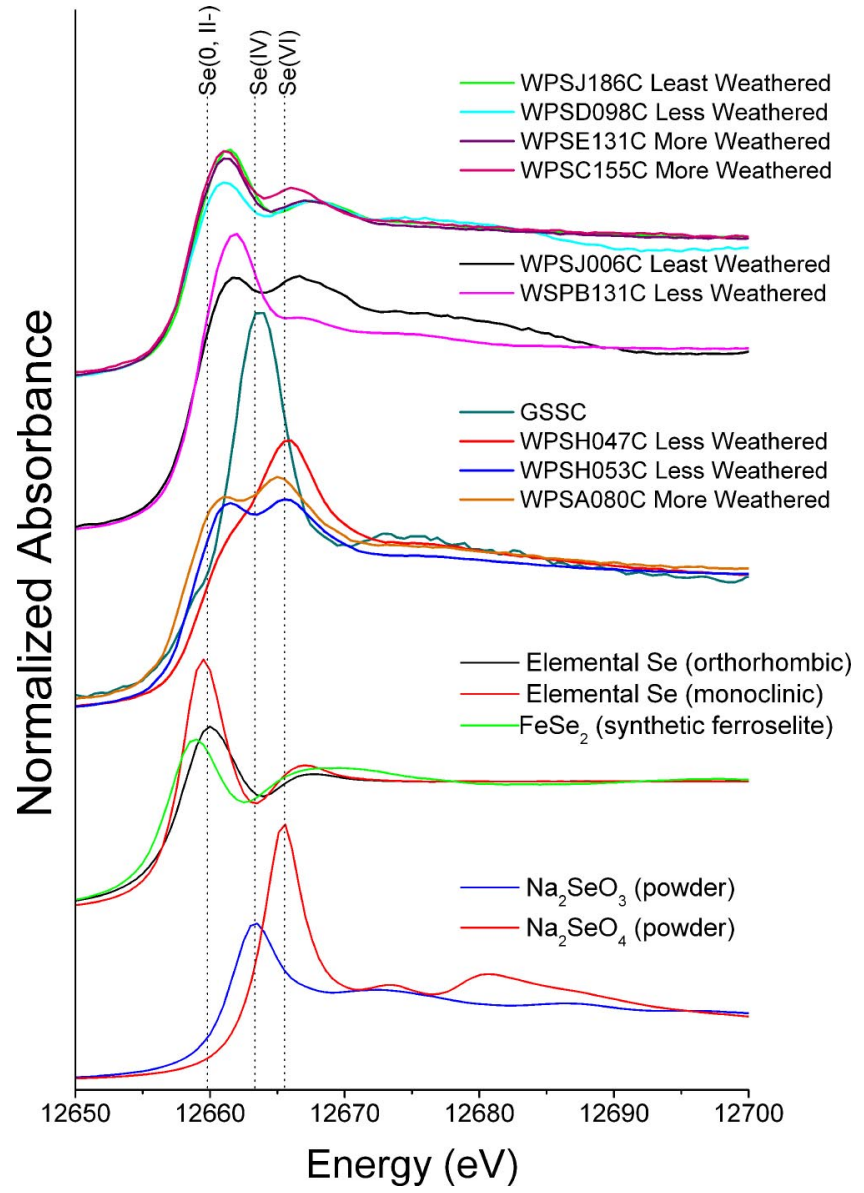

FIG. 8. (Color) Selenium XANES spectra from bulk rock samples and standards.

associated with iron and $\mathrm{S}$ in the Permian sedimentary formations. Additional information on Se speciation in the shale requires spectroscopy to probe Se oxidation state and molecular coordination.

\section{Bulk XANES}

Selenium XANES spectra for bulk samples are shown in Fig. 8. Based on the XANES we conclude that the Se in the shale samples has several oxidation states, with peaks between $\mathrm{Se}(-\mathrm{II})$ and $\mathrm{Se}(\mathrm{VI})$ species. The peaks that fall between $\mathrm{Se}(0)$ and $\mathrm{Se}(\mathrm{IV})$ may represent organic species or be a result of linear combinations of multiple species. Principal component analysis was done on these samples to determine the number of species present. The minimum number of components necessary to reproduce the spectral set $(n=10)$ was 6. Target transforms of 15 reference materials (listed in Table II) indicated that mandarinoite, an $\mathrm{Fe}-\mathrm{O}-$ selenite mineral, was the only acceptable target. Five references were deemed moderately acceptable (monoclinic elemental Se, three organic Se species, and seleno-disulfide). Thus the PCA and target transform results were inconclusive. However, it is clear that Se species representing reduced $\mathrm{Se}(-\mathrm{II}, 0)$ and oxidized $\mathrm{Se}(\mathrm{IV}, \mathrm{VI})$ compounds are present in the samples, indicating Se speciation in natural environments is heterogeneous. 


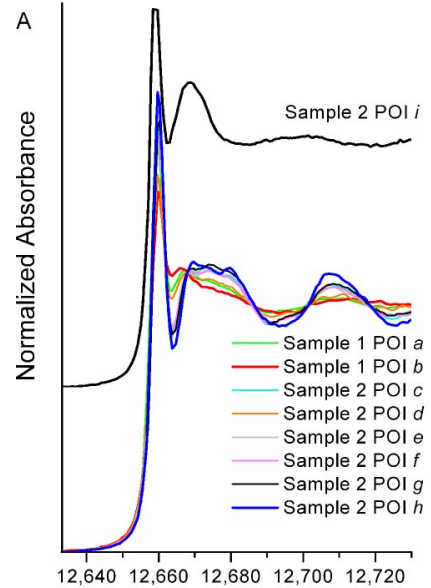

Energy (eV)

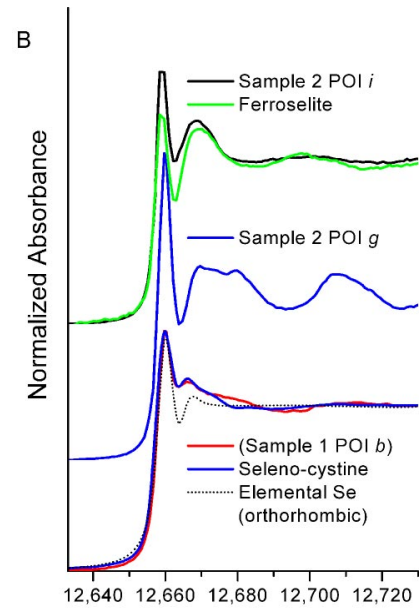

Energy (eV)
FIG. 9. (Color) Selenium micro-XANES spectra for samples 1 and 2; (a) contains the spectra for all points. Spectra from the series in (a) that are considered to be spectral end members (unique species) are shown with standards in (b).

Despite the fact that the bulk samples have three degrees of assigned weathering, least, less, and more, there was no clear trend in Se oxidation state among the samples. It was expected that the least weathered sample would contain reduced species, the more weathered samples would contain oxidized species, and the less weathered samples would contain a combination of reduced and oxidized species. The presence of oxidized species in the least weathered sample may be an artifact from sample collection (drilling), preparation (grinding), and/or storage in aerobic environments. Alternatively the least weathered samples may actually have some unexpected weathering. Knudsen and Gunter ${ }^{33}$ and Herring and Grauch ${ }^{34}$ proposed that the enrichment of Se in the middle waste shale is a result of weathering of Se from the overlying materials and precipitation in the less permeable middle waste shale, making it possible for $\mathrm{Se}$ in the least weathered material to exist in the mobile, oxyanionic, $\mathrm{Se}(\mathrm{IV})$ and $\mathrm{Se}(\mathrm{VI})$ species. Due to the presence of organic matter, microbes, and lack of oxygen, diagenic elemental and metal selenides would be expected, ${ }^{35}$ however, the presence of some nonreduced Se cannot be ruled out. Perkins and Foster $^{11}$ also observed Se(IV) species in weathered samples.

\section{Micro-XANES}

Preliminary XANES scans of 12 spots in shale samples 1 and 2 were completed. Spots that were deemed unique were further scanned using a full XANES scan. MicroXANES from these spots $[a-i$ on the $X Y$ maps (Figs. 3 and 4)] are presented in Fig. 9(a). In the XANES of spots $a-h$ there are distinct isosbetic points, suggesting that these data are composed of linear combinations of two end-members. Point of interest $i$ is distinct, and is plotted offset from others in Fig. 9(a) to aid in visual interpretation. Results from PCA confirmed that $98 \%$ of the variance in the nine spectra can be accounted for by three components, suggesting that samples 1 and 2 contain three unique Se species [Fig. 9(b)]. Target transforms confirmed that ferroselite and seleno-cystine were acceptable matches for the components. An acceptable match for the third component was not found.

XANES from spot $g$ is similar to seleniferous pyrite/ marcasite as identified by Perkins and Foster. ${ }^{11}$ This standard was not available to make a direct comparison, however qualitatively the features in the XANES from spot $g$ are the same as those for the Se-pyrite/marcasite standard reported in Perkins and Foster. ${ }^{11}$ Perkins and Foster ${ }^{11}$ used bulk XANES analysis to identify seleniferous pyrite/macrcasite in the middle waste shale samples from WPRA. Howard ${ }^{31}$ reported that when the concentration ratio of $\mathrm{H}_{2} \mathrm{Se}$ is high relative to $\mathrm{H}_{2} \mathrm{~S}$, and excess iron is present, ferroselite is thermodynamically stable relative to elemental Se and pyrite. However, Howard ${ }^{31,36}$ suggested that when the concentration of $\mathrm{H}_{2} \mathrm{Se}$ is below a critical point, pyrite is stable, and Se will form either elemental $\mathrm{Se}$ or a $\mathrm{Se}$-pyrite solid solution.

The micro-XANES spectrum from spot $b$, which is a spectral end member, has XANES features that most closely match the spectrum of seleno-cystine [Fig. 9(b)]. Black shales contain high concentrations of organic carbon compounds, including sulfur compounds. ${ }^{37}$ The similarity in the XANES from spot $b$ with seleno-cystine is likely a result of a di-sulfide-type bond involving either two $\mathrm{Se}$ atoms or a $\mathrm{Se}$ and $\mathrm{S}$ atom, as in seleno-cystine, but does not necessarily indicate that seleno-cystine is the molecular form of Se in the shale. In fact, the EXAFS structure directly following the XANES region of spot $b$ (data not shown) is clearly distinct from seleno-cystine and elemental Se. The concomitant presence of iron at this spot suggests that the Se may be present bonded into an organic molecule mixed with colloidal iron sulfide minerals, or possibly some type of iron-selenide carbon compound, such as a hydrogenase.

There are three possible mechanisms through which organic Se can form in the shales: (1) detrital Se introduced from plant materials, particularly since plants tend to shuttle Se into amino acids such as cystine/cysteine for detoxification, ${ }^{38}$ possibly altered by catagenic processes; ${ }^{35}$ (2) abiotic, nucleophillic replacement of organic functional groups by reduced $\mathrm{Se}(-\mathrm{II})$; $^{39}$ or (3) microbial by-products that formed in the anaerobic sedimentary environment. Herring and Grauch $^{34}$ used factor analysis to show that the Se in the Meade Peak Formation materials was highly correlated with organic $\mathrm{C}$ and total $\mathrm{S}$, which supports our observation that an organically-bonded Se compound is present in the shale. Bond ${ }^{29}$ performed total Se analyses on methylene chloride $(\mathrm{MeCl})$ extracts of middle waste shale from the WPRA with varying amounts of weathering. Methylene chloride is a selective extractant for semi-volatile organic compounds. ${ }^{40}$ The percentage of $\mathrm{MeCl}$ extractable Se in the bulk rock ranged from $0.4 \%$ to $2.6 \%$, with the unweathered sample containing the most $\mathrm{MeCl}$ extractable Se. Additional analyses of the extracts by gas chromatography mass spectroscopy indicated that $\mathrm{C} 8$ to $\mathrm{C} 25$ hydrocarbons were present. $^{29}$

Spot $i$ has a XANES spectra similar to that of ferroselite [Fig. 9(b)]. As discussed earlier, ferroselite is considered to be a stable mineral formed when reduced Se and Fe concentrations are high relative to sulfide concentrations. Of the 12 


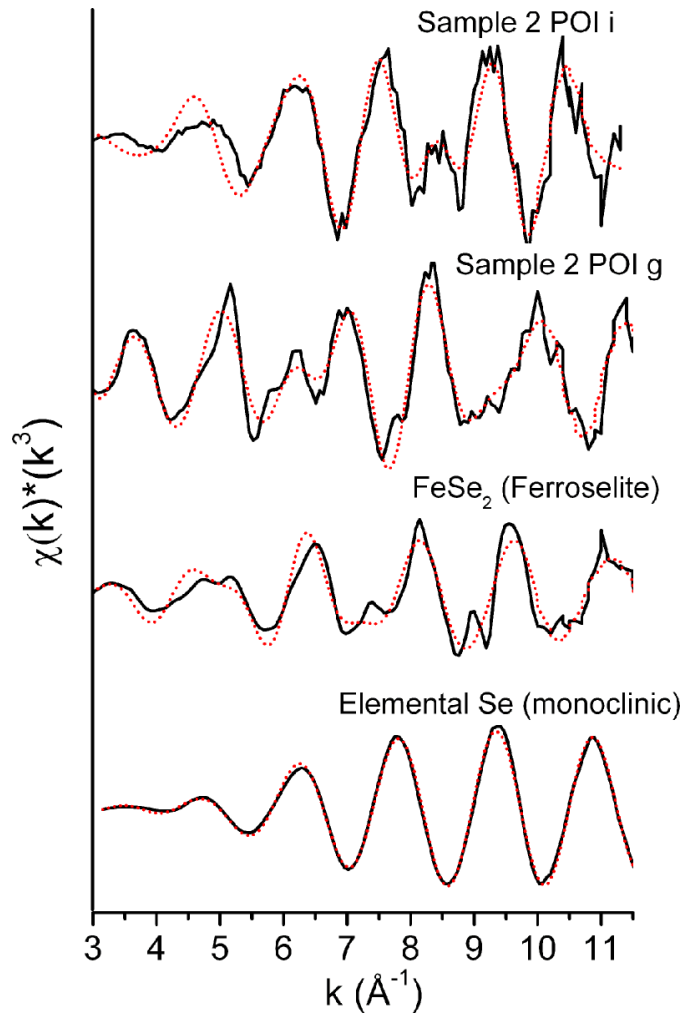

FIG. 10. (Color) $\mathrm{k}^{3}$ weighted $\chi$ spectra of Se standards and POI $g$ and $i$ from sample 2 . The red dotted lines are best fits. The parameters used in fitting are reported in Tables III and IV.

spots measured on the two samples, only one had XANES that resembled the XANES from ferroselite. The other spots had XANES spectra indicative of mixtures of Se-substituted pyrite/marcasite and a diselenide organic compound [see Fig. 9(a)]. Although marcasite and ferroselite are isostructural, their unit cell dimensions differ, and thus should result in distinct XANES from Se-substituted pyrite/marcasite (see Table IV for theoretical interatomic distances). Dzharkenite, an iron selenide isostructural to pyrite, or achavalite, an iron selenide isostructural to mackinawite, were not available as standard references. Iron selenides are commonly found together with iron sulfides, and the geochemistry of Se is largely controlled by $\mathrm{Fe}^{31}$ The kinetic and thermodynamic processes associated with diagenesis of these reduced iron selenide minerals are poorly understood, but related to temperature, redox potential, relative concentrations, and speciation. A summary reaction for the formation of ferroselite is

$$
\mathrm{FeS}_{2}+2 \mathrm{H}_{2} \mathrm{Se} \leftrightarrow \mathrm{FeSe}_{2}+2 \mathrm{H}_{2} \mathrm{~S} .
$$

Howard ${ }^{31}$ proposed that for this reaction to occur the $\mathrm{H}_{2} \mathrm{~S} / \mathrm{H}_{2} \mathrm{Se}$ ratio must be less than $10^{-2.6}$, and suggested that elemental Se is a reactant. Elemental Se was not detected in our samples or the XANES spectra of the Perkins and Foster ${ }^{11}$ study. Grauch et al. ${ }^{35}$ identified elemental Se in the middle waste shale using SEM-EDS. Although Howard ${ }^{31}$ proposed possible reaction mechanisms for the formation of ferroselite in a pyrite environment, the actual reactions occurring in the environment are not known; highlighting the need for accurate speciation studies.

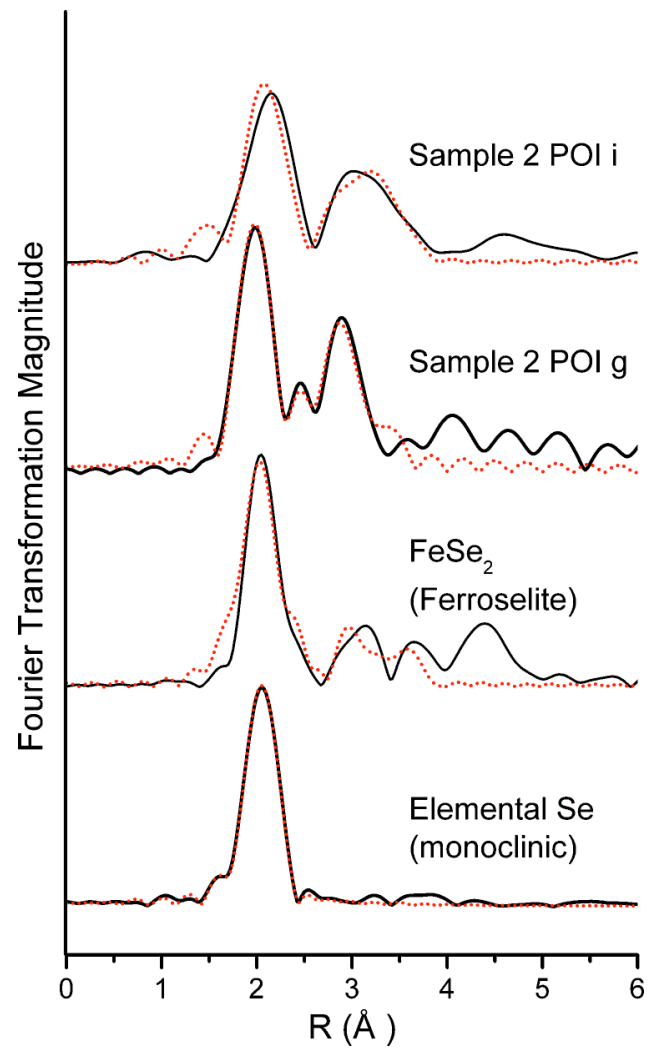

FIG. 11. (Color) Fourier transformation and best fits for standards and POI $g$ and $i$. The red dashed lines are best fits. The parameters used in fitting are reported in Tables III and IV.

Analysis of the Se XANES indicated that there are three species present in the middle waste shale: selenium substituted pyrite/marcasite, organic diselenide compounds, and an iron selenide such as ferroselite. We found no evidence of elemental Se or oxidized $\mathrm{Se}$ in the freshly cleaved shale samples. Previous micro-analyses have suggested that $\mathrm{Zn}$ and $\mathrm{Cu}$ selenides are also present in the middle waste shale. ${ }^{11}$ We did not detect these species; however, there were positive correlations with these elements in the micro-SXRF mapping. The lack of detection of these metal selenides in the XANES data may be due to the low concentrations present relative to the iron selenides, i.e., the $\mathrm{Zn}$ or $\mathrm{Cu}$ selenides may be present as small isolates in the iron-sulfide/selenides.

\section{E. Micro-EXAFS spectroscopy}

To further identify the mineralogy of the selenium present in the middle waste shale we collected microEXAFS spectra on end-member spots $i$ and $g$. A limited range of micro-EXAFS data were collected for spot $b$ because it was not recognized as an end member at the time of data collection. While the near edge spectra (XANES) are sensitive to oxidation state and first shell coordination environment, EXAFS spectra are sensitive to backscattering off of multiple atomic shells, making this technique a sensitive probe for molecular composition and structure.

Micro-EXAFS spectra and their Fourier transforms for the points of interest are shown in Figs. 10 and 11. All $\chi$ spectra show complex oscillations, indicating that the Se is surrounded by several different backscattering atoms at dif- 
TABLE III. Fit results for sample 2 POI $g$ and $i$ and ferroselite and elemental Se (monoclinic) standards.

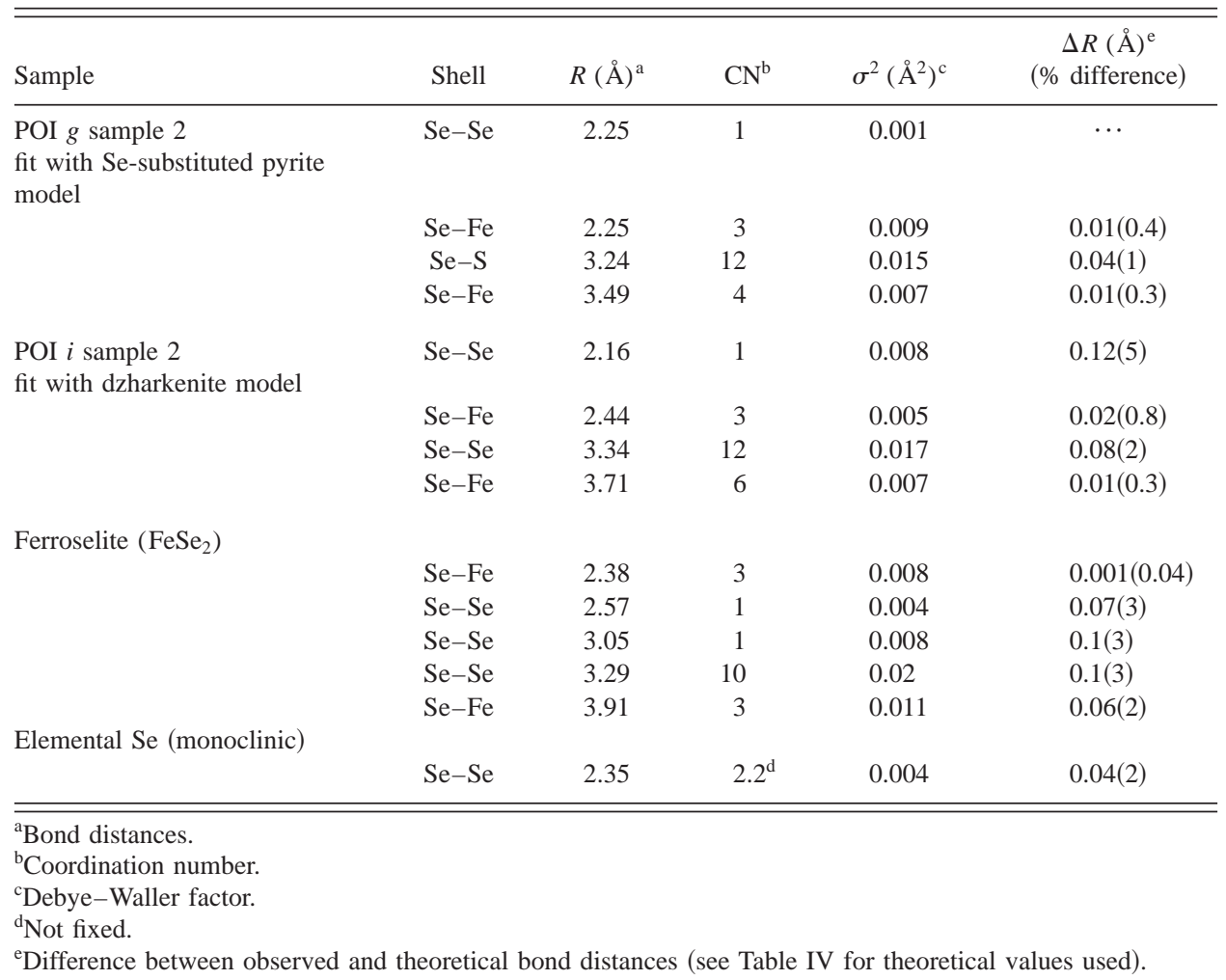

ferent bond lengths. The $\chi$ spectrum for the elemental monoclinic Se standard (Fig. 10) shows a simple sinusoidal pattern characteristic of a well-ordered homogeneous atomic environment surrounding the central Se atom.

To further elucidate the local atomic environment surrounding Se the $\chi$ spectra for spots $i$ and $g$ were Fourier transformed (FT) to isolate the phase and amplitude contributions. Peaks in the FT correspond to atomic backscatterers surrounding the central Se atom (offset by a phase shift). In cases where multiple atoms exist at similar bond distances, separation of the backscatterers by FT is difficult. For example, in the mineral ferroselite the first atomic shell surrounding Se has four atoms between 2.34 and $2.5 \AA$ (three Fe atoms and one Se atom, Table IV). In the FT of the ferroselite EXAFS spectra the peak at $2.05 \AA$ corresponds to backscattering off of these atoms. The lack of resolution of the two atomic backscatterers in the FT illustrates the limitations of resolving molecular structures that have multiple shells with short distances from the central atom.

To evaluate the sensitivity and robustness of fitting, EXAFS data from a well-characterized synthesized ferroselite mineral were fit (see Table III). Derived bond distances and coordination numbers for the first shell were accurate. The ten Se atoms occurring between 3.29 and $3.58 \AA$ in ferroselite were considered to be a single shell that was fit at $3.29 \AA$. The Se-Se backscatterer corresponding to this feature has ten atoms with a theoretical weighted average of $3.39 \AA$. The $\sigma^{2}$ for this shell was $0.02 \AA^{2}$ reflecting the high distribution of bond distances for this shell as compared to the other shells. A similar approach was used to fit the three theoretical Fe atoms located between 3.74 and $3.91 \AA$ A. Fitting of five shells in the ferroselite EXAFS spectrum resulted in bond distances that were consistent with the mineral structure [differences between fit and theoretical bond distances $(\Delta R)$ are shown in Table III], and markedly distinct from the polymorph dzharkenite. The peak centered at $4.4 \AA$ in the FT is due to contributions from several single and multiple scattering paths. The position of this feature was accounted for in a FEFF simulation of ferroselite, however, it could not be fit because of the overconstraint of the fitting routine. Thus, based on the results of fitting ferroselite, we conclude that EXAFS spectroscopy can be used to resolve the molecular coordination of Se in iron-selenide minerals.

The EXAFS from spot $g$ was fit using theoretical backscatterers from pyrite. The model fit resulted in four atomic shells (Table III). The first atomic shell surrounding Se contains three $\mathrm{Fe}$ atoms at $2.25 \AA$. Attempts to fit $\mathrm{S}$ in this shell with and without iron were unsuccessful. One Se atom at $2.25 \AA$ was fit, but did not improve the quality of the fit, suggesting it has a minimal contribution. Ideal pyrite has three Fe atoms at $2.26 \AA$ and one $\mathrm{S}$ atom at $2.14 \AA$. Marcasite has a similar first atomic shell structure with $\mathrm{S}$ atoms at 2.21 and Fe between 2.23 and $2.25 \AA$. The third shell was fit with $12 \mathrm{Se}$ atoms at $3.24 \AA$, which is close to the weighted average for these twelve atoms in pyrite or marcasite (Table IV), but distinctly shorter than the expected distance for dzharkenite or ferroselite. The fourth atomic shell was fit with four Fe atoms at $3.49 \AA$, which is most similar to the bond distance observed in pyrite. Thus we hypothesize that the mineral at spot $g$ is a Se-substituted pyrite based on three observations: (1) the first shell Fe-bond distance is distinctly shorter than the $\mathrm{FeSe}_{2}$ polymorphs; (2) the second and higher shell backscattering atoms occur at similar bond distances as marcasite/pyrite (a slightly better match for pyrite); and (3) 
TABLE IV. Theoretical bond distances and coordination numbers for Se and S-bearing minerals.

\begin{tabular}{|c|c|c|c|}
\hline Sample & Shell & $R(\AA)^{\mathrm{a}}$ & $\mathrm{CN}^{\mathrm{t}}$ \\
\hline \multicolumn{4}{|c|}{ Ferroselite $\left(\mathrm{FeSe}_{2}\right)^{\mathrm{d}}$} \\
\hline & $\mathrm{Se}-\mathrm{Fe}$ & $\begin{array}{l}2.34-2.38 \\
\left(\bar{X}^{\mathrm{c}}=2.37\right)\end{array}$ & 3 \\
\hline & $\mathrm{Se}-\mathrm{Se}$ & 2.50 & 1 \\
\hline & $\mathrm{Se}-\mathrm{Se}$ & 3.15 & 1 \\
\hline & $\mathrm{Se}-\mathrm{Se}$ & $\begin{array}{l}3.29-3.58 \\
\left(\bar{X}^{\mathrm{c}}=3.39\right)\end{array}$ & 10 \\
\hline & $\mathrm{Se}-\mathrm{Fe}$ & $\begin{array}{l}3.74-3.91 \\
\left(\bar{X}^{\mathrm{c}}=3.85\right)\end{array}$ & 3 \\
\hline \multicolumn{4}{|c|}{ Dzharkenite $\left(\mathrm{FeSe}_{2}\right)^{\mathrm{e}}$} \\
\hline & $\mathrm{Se}-\mathrm{Se}$ & 2.28 & 1 \\
\hline & $\mathrm{Se}-\mathrm{Fe}$ & 2.42 & 3 \\
\hline & $\mathrm{Se}-\mathrm{Se}$ & $\begin{array}{c}3.29-3.55 \\
\left(\bar{X}^{\mathrm{c}}=3.42\right)\end{array}$ & 12 \\
\hline & $\mathrm{Se}-\mathrm{Fe}$ & $\begin{array}{l}3.67-3.87 \\
\left(\bar{X}^{\mathrm{c}}=3.72\right)\end{array}$ & 4 \\
\hline & $\mathrm{Se}-\mathrm{Fe}$ & 4.75 & 3 \\
\hline \multicolumn{4}{|l|}{ Pyrite $^{d}$} \\
\hline & $\mathrm{S}-\mathrm{S}$ & 2.14 & 1 \\
\hline & $\mathrm{S}-\mathrm{Fe}$ & 2.26 & 3 \\
\hline & $\mathrm{S}-\mathrm{S}$ & $\begin{array}{l}3.08-3.32 \\
\left(\bar{X}^{\mathrm{c}}=3.20\right)\end{array}$ & 12 \\
\hline & $\mathrm{S}-\mathrm{Fe}$ & $\begin{array}{l}3.43-3.61 \\
\left(\bar{X}^{\mathrm{c}}=3.48\right)\end{array}$ & 4 \\
\hline & $\mathrm{S}-\mathrm{Fe}$ & 4.44 & 3 \\
\hline \multicolumn{4}{|c|}{ Marcasite $^{\mathrm{d}}$} \\
\hline & $S-S$ & 2.21 & 1 \\
\hline & $\mathrm{S}-\mathrm{Fe}$ & $\begin{array}{l}2.23-2.25 \\
\left(\bar{X}^{\mathrm{c}}=2.24\right)\end{array}$ & 3 \\
\hline & $\mathrm{S}-\mathrm{S}$ & $\begin{array}{l}2.97-3.38 \\
\left(\bar{X}^{\mathrm{c}}=3.19\right)\end{array}$ & 11 \\
\hline & $\mathrm{S}-\mathrm{Fe}$ & $\begin{array}{l}3.48-3.60 \\
\left(\bar{X}^{\mathrm{c}}=3.56\right)\end{array}$ & 3 \\
\hline
\end{tabular}

${ }^{\mathrm{a} B o n d}$ distances.

${ }^{\mathrm{b}}$ Coordination number.

${ }^{\mathrm{c}}$ Weighted average used for $\Delta \mathrm{R}$ calculation (see Table III).

${ }^{\mathrm{d}}$ Reference 43.

${ }^{\mathrm{e}}$ Reference 44.

the similarity of the XANES to the Se-substituted marcasite/ pyrite presented by Perkins and Foster. ${ }^{11}$

Fitting the EXAFS data from spot $i$ resulted in four atomic shells. The fitted bond distances for the first four atomic shells agreed with the mineral dzharkenite as opposed to ferroselite (Tables III and IV). Specifically, in ferroselite the first shell Se atom is at a much longer bond distance than the three iron atoms, while in dzharkenite this is reversed. The third and fourth shells were fit with $\mathrm{Se}$ and $\mathrm{Fe}$ atoms, respectively, resulting in bond distances consistent with the weighted average for these atomic shells in dzharkenite. Based on the fit of the first four atomic shells having similar bond distances as the theoretical structure of dzharkenite, we hypothesize that spot $i$ is dzharkenite and not ferroselite.

Dzharkenite is a rare mineral with only a few known occurrences. ${ }^{32}$ However, it has been reported as a mineral in solid solution with pyrite. ${ }^{32}$ Thus, the mineral is likely present in the shale as a $\mathrm{Fe}-\mathrm{Se}-\mathrm{S}$ mineral, but with Se dominating the composition such that it has a dzharkenite struc- ture rather than a Se-substituted pyrite or marcasite structure.

The analyses of the Se micro-EXAFS spectra provided insights into the identity of two of the three end members we observed. Kulp and Pratt ${ }^{41}$ analyzed selenium speciation in chalk and shale collected from South Dakota and Wyoming using selective sequential extractions. Based on their results they hypothesized that the Se was present in the rocks predominantly as organic Se compounds and di-selenide minerals (e.g., ferroselite). Therefore the macroscopic observations of Kulp and Pratt ${ }^{41}$ support our findings. By using a molecular level technique we have extended the general observations of Kulp and Pratt ${ }^{41}$ and identified specific mineral and molecular speciation of Se in the shale. Given the difficulty in interpreting mineral structures due to sample heterogeneity, microscopic synchrotron-based XRF, XANES, and EXAFS spectroscopy allows for unique insights into Se speciation within heterogeneous materials such as rocks. We know of no other technique better suited for investigating the speciation of elements with bulk concentrations too low for traditional techniques.

\section{CONCLUSION}

The most commonly reported forms of Se in shale are Se-substituted pyrite, ${ }^{6,11,31,42}$ or precipitation of metal selenides. ${ }^{41}$ However, results of past studies are based on standard micro-analytical techniques, bulk EXAFS spectroscopy, and chemical extractions. In this study we used advanced microscopic spectroscopy to resolve the specific speciation of Se that occurs in shale. Our results suggest that there are three distinct phases in the shale that contain Se; dzharkenite, an organic di-selenide, and Se-substituted pyrite. In all of these phases Se existed in negative oxidation states, indicating that the oxidized Se present in weathered shales is a result of oxidative weathering of the reduced mineral Se to elemental Se, selenite, or selenate.

Improved knowledge of the forms of Se present in shale will allow for a better understanding of the biogeochemical cycling of Se as the Se-bearing rocks begin to weather. Oxidative breakdown of the various selenides occurring in the shale will lead to increased mobility and bioavailability of Se. These reactions are likely rate controlled. We are not aware of differences in the solubility or dissolution rates of dzharkenite, Se-substituted pyrite, and organic selenide compounds. However, by knowing the Se minerals and compounds that are relevant, further studies can be undertaken to determine how Se is released from Se-bearing mine waste. Such studies are important in assessing environmental risks associated with mining areas in the WPRA, where Sebearing rocks have been displaced from the stable, slowly weathering strata, to the surficial environment in which weathering processes are much more rapid.

\section{ACKNOWLEDGMENTS}

Funding for this project was provided by US-EPA grant ID\#X970339010 and by a grant from the J.R. Simplot Company. The Advanced Light Source is supported by the Director, Office of Science, Office of Basic Energy Sciences, Materials Sciences Division, of the U.S. Department of Energy 
under Contract No. DE-AC03-76SF00098 at Lawrence Berkeley National Laboratory. Research carried out (in whole or in part) at the National Synchrotron Light Source, Brookhaven National Laboratory is supported by the U.S. Department of Energy, Division of Materials Sciences and Division of Chemical Sciences, under Contract No. DEAC02-98CH10886. Assistance from Brian Hart and Sirine Fakara is appreciated.

${ }^{1}$ P. Mislevy, W. G. Blue, J. A. Stricker, B. C. Cook, and M. J. Vice, in Reclamation of Drastically Disturbed Lands, edited by R. I. Barnhisel, R. G. Darmody, and W. L. Daniels (American Society of Agronomy, Madison, WI, 2000), Vol. 41, 961 pp.

${ }^{2}$ G. R. Mansfield, U.S. Geol. Surv. Prof. Pap. 152, U. S. Government Print Office (1927).

${ }^{3}$ A. C. Knudsen, Ph.D. dissertation, University of Idaho, 2002.

${ }^{4}$ G. Desborough, E. DeWitt, J. Jones, A. Meier, and G. Meeker, U. S. Geol. Surv. Open-File Rep. No. 99-129, 1999, p. 20.

${ }^{5}$ G. N. Schrauzer, J. Nutr. 130, 1653 (2000).

${ }^{6}$ T. S. Presser and W. C. Swain, Appl. Geochem. 5, 703 (1990).

${ }^{7}$ P. T. Zawislanski, S. M. Benson, R. Terberg, and S. E. Borglin, Environ. Sci. Technol. 37, 2415 (2003)

${ }^{8}$ S. M. Workman, Report No. AG 680, 1983; S. E. Fisher, F. F. Munshower, and F. Parady, in Reclaiming Mine Soils and Overburden in the Western United States: Analytic Parameters and Procedures, edited by R. D. Williams and G. E. Schuman (Soil Conservation Society of America, Ankeny, IA, 1987), p. 109.

${ }^{9}$ K. F. Hayes, A. L. Roe, G. E. Brown, K. O. Hodgson, J. O. Leckie, and G. A. Parks, Science 238, 783 (1987).

${ }^{10}$ G. A. Desborough, U. S. Geol. Surv. Open-File Rep. No. 77-341, 1977, p. 20.

${ }^{11}$ R. B. Perkins and A. L. Foster, in Life Cycle of the Phosphoria Formation: From Deposition to Post-Mining Environment, edited by J. R. Hein (Elsevier, Amsterdam, 2004), Vol. 8, 251 pp.

${ }^{12}$ I. J. Pickering, G. E. Brown, Jr., and T. K. Tokunaga, Environ. Sci. Technol. 29, 2456 (1995).

${ }^{13}$ A. Manceau, M. A. Marcus, and N. Tamura, in Applications of Synchrotron Radiation in Low-Temperature Geochemistry and Environmental Sciences, edited by P. A. Fenter, M. L. Rivers, N. C. Sturchio et al. (Geochemical Society and Mineralogical Society of America, Washington, DC, 2002), Vol. 49, 341 pp.

${ }^{14}$ D. G. Strawn, H. E. Doner, M. Zavarin, and S. McHugo, Geoderma 108, 237 (2002).

${ }^{15}$ T. K. Tokunaga, S. R. Sutton, S. Bujt, P. Nuessle, and G. Shea-McCarthy, Environ. Sci. Technol. 32, 1092 (1998).

${ }^{16}$ J. R. Herring, G. A. Desborough, S. A. Wilson, R. G. Tysdal, R. I. Grauch, and M. E. Gunter, U. S. Geol. Surv. Open-File Rep. No. 99-147-A, 1999, p. 24

${ }^{17}$ J. R. Herring, R. I. Grauch, G. A. Desborough, S. A. Wilson, and R. G. Tysdal, U. S. Geol. Surv. Open-File Rep. No. 99-147-C, 2000, p. 35.

${ }^{18}$ J. R. Herring, R. I. Grauch, G. A. Desborough, S. A. Wilson, and R. G.
Tysdal, U. S. Geol. Surv. Open-File Rep. No. 99-147-D, 2000, p. 38.

${ }^{19}$ J. R. Herring, S. A. Wilson, L. A. Stillings, A. C. Knudsen, M. E. Gunter, R. G. Tysdal, R. I. Grauch, G. A. Desborough, and R. A. Zielinski, U. S. Geol. Surv. Open-File Rep. No. 99-147-B, 2000, p. 34.

${ }^{20}$ C. G. Warren, Econ. Geol. 63, 418 (1968).

${ }^{21}$ M. A. Marcus, A. A. MacDowell, R. Celestre, A. Manceau, T. Miller, H. A. Padmore, and R. E. Sublett, J. Synchrotron Radiat. 11, 239 (2004)

${ }^{22}$ F. W. Lytle, R. B. Greegor, D. R. Sandstom, E. C. Marques, J. Wond, C. L. Spiro, G. P. Huffman, and F. E. Huggins, Nucl. Instrum. Methods Phys. Res. A 226, 542 (1984).

${ }^{23}$ J. Newville, J. Synchrotron Radiat. 8, 322 (2001).

${ }^{24}$ A. L. Ankudinov, B. Ravel, J. J. Rehr, and S. D. Conradson, Phys. Rev. B 58, 7565 (1998).

${ }^{25}$ T. Ressler, J. Synchrotron Radiat. 5, 118 (1998).

${ }^{26}$ B. C. Bostick and S. Fendorf, Geochim. Cosmochim. Acta 67, 909 (2003).

${ }^{27}$ S. Beauchemin, D. Hesterberg, and M. Beauchemin, Soil Sci. Soc. Am. J. 66, 83 (2002)

${ }^{28}$ P. Frank, B. Heman, R. M. K. Carlson, and K. O. Hodgson, Inorg. Chem. 33, 3794 (1994); K. Xia, F. Weesner, W. F. Bleam, P. R. Bloom, U. L. Skyllberg, and P. A. Helmke, Soil Sci. Soc. Am. J. 62, 1240 (1998),

${ }^{29}$ M. M. Bond, Master of Science thesis, University of Idaho, 1999.

${ }^{30}$ J. P. Munkers, Master of Science thesis, University of Idaho, 2000.

${ }^{31}$ J. H. Howard, Geochim. Cosmochim. Acta 41, 1665 (1977).

${ }^{32}$ V. A. Yakovleva, E. V. Belogub, and K. A. Novoselov, Miner. Mag. 67, 355 (2003).

${ }^{33}$ A. C. Knudsen and M. E. Gunter, in Phosphates-Geochemical, Geobiological, and Materials Importance, edited by M. J. Kohn, J. Rakovan, and J. M. Hughes (Mineralogical Society of America, Washington, DC, 2003).

${ }^{34} \mathrm{~J}$. R. Herring and R. I. Grauch, in Life Cycle of the Phosphoria Formation, edited by J. R. Hein (Elsevier, Amsterdam, 2004), Vol. 8, 321 pp.

${ }^{35}$ R. I. Grauch, G. A. Desborough, G. P. Meeker, A. L. Foster, R. G. Tysdal, J. R. Herring, H. A. Lowers, B. A. Ball, R. A. Zielinski, and E. A. Johnson, in Life Cycle of the Phosphoria Formation: From Deposition to the PostMining Environment, edited by J. R. Hein (Elsevier, Amsterdam, 2004), Vol. 8, $189 \mathrm{pp}$

${ }^{36}$ R. G. Coleman and M. Delevaux, Econ. Geol. 52, 499 (1957).

${ }^{37}$ H. F. Passier and G. D. Lang, Proceedings of the Ocean Drilling Program, Scientific Results, 1998, Vol. 160, p. 249; M. L. Tuttle, C. A. Rice, and M. B. Goldhaber, in Geochemistry of Sulfur in Fossil Fuels, edited by W. L. Orr and C. M. White (American Chemical Society, Washington, DC, 1990), Vol. 429, 114 pp.

${ }^{38}$ J. F. Thompson, I. K. Smith, and J. T. Madison, in Sulfur in Agriculture, edited by M. A. Tabatabai (ASA, CSSA, and SSSA, Madison, WI, 1986), Vol. 27, 57 pp.

${ }^{39}$ A. Vairavamurthy and K. Mopper, in Biogenic Sulfur in the Environment, edited by E. S. Saltzman and W. J. Cooper (American Chemical Society, Washington, DC, 1989), Vol. 393, 231 pp.

${ }^{40}$ M. L. Tracy and G. Möller, J. Assoc. Off. Anal. Chem. 73, 404 (1990).

${ }^{41}$ T. R. Kulp and L. M. Pratt, Geochim. Cosmochim. Acta 68, 3687 (2004).

${ }^{42}$ D. J. Velinsky and G. A. Cutter, Anal. Chim. Acta 235, 419 (1990).

${ }^{43}$ R. W. G. Wyckoff, Crystal Structures (Wiley \& Sons, New York, 1963), Vol. 1.

${ }^{44}$ J. A. Mandarino, Miner. Record 27, 115 (1996). 